University of Wollongong

Research Online

Faculty of Business - Papers (Archive)

Faculty of Business and Law

$1-1-2016$

\title{
The environmental Kuznets curve and the structural change hypothesis
}

Simone Marsiglio

University of Wollongong, simonem@uow.edu.au

Alberto Ansuategi

University of The Basque Country

Maria Carmen Gallastegui

University of The Basque Country

Follow this and additional works at: https://ro.uow.edu.au/buspapers

Part of the Business Commons

Research Online is the open access institutional repository for the University of Wollongong. For further information contact the UOW Library: research-pubs@uow.edu.au 


\title{
The environmental Kuznets curve and the structural change hypothesis
}

\begin{abstract}
We provide a very simple macroeconomic investigation of the role that structural changes might play in generating inverted U-shaped income-pollution relationships. Differently from previous research which mainly focuses on empirical, static or general equilibrium models, we develop a standard balanced growth path (BGP) analysis. We show that along the BGP equilibrium an inverted U-shaped incomepollution relationship may occur as a response to structural changes, but whether this is the case or not it will crucially depend upon the magnitude of a production externality parameter. Moreover, we show that the negative relationship between income and pollution can only be a transitory phenomenon, and in the long run pollution will increase as income rises, generating overall an $\mathrm{N}$-shaped pattern.
\end{abstract}

\section{Keywords}

kuznets, curve, structural, environmental, change, hypothesis

Disciplines

Business

\section{Publication Details}

Marsiglio, S., Ansuategi, A. \& Gallastegui, M. Carmen. (2016). The environmental Kuznets curve and the structural change hypothesis. Environmental and Resource Economics, 63 (2), 265-288. 


\title{
The Environmental Kuznets Curve and the Structural Change Hypothesis
}

\author{
Simone Marsiglio ${ }^{1} \cdot$ Alberto Ansuategi $^{2}$. \\ Maria Carmen Gallastegui ${ }^{2}$
}

Accepted: 23 July 2015 / Published online: 5 August 2015

C Springer Science+Business Media Dordrecht 2015

\begin{abstract}
We provide a very simple macroeconomic investigation of the role that structural changes might play in generating inverted U-shaped income-pollution relationships. Differently from previous research which mainly focuses on empirical, static or general equilibrium models, we develop a standard balanced growth path (BGP) analysis. We show that along the BGP equilibrium an inverted U-shaped income-pollution relationship may occur as a response to structural changes, but whether this is the case or not it will crucially depend upon the magnitude of a production externality parameter. Moreover, we show that the negative relationship between income and pollution can only be a transitory phenomenon, and in the long run pollution will increase as income rises, generating overall an $\mathrm{N}$-shaped pattern.
\end{abstract}

Keywords Environmental Kuznets curve $\cdot$ Economic growth $\cdot$ Structural change

JEL Classification $\mathrm{O} 40 \cdot \mathrm{O} 41 \cdot \mathrm{Q} 50 \cdot \mathrm{Q} 56$

We are grateful to Baran Doda and Andrew John for insightful discussions. We also wish to thank the participants to the WCERE 2014 (Istanbul, Turkey), WAMS 2014 (Melbourne, Australia) and JCU seminar for helpful comments and suggestions. We are indebted to two anonymous referees for their constructive comments helping us to substantially improve our paper.

$\bowtie \quad$ Alberto Ansuategi

alberto.ansuategi@ehu.es

Simone Marsiglio

simonem@uow.edu.au

Maria Carmen Gallastegui

mariacarmen.gallastegui@ehu.es

1 School of Accounting, Economics and Finance, University of Wollongong, Northfields Avenue, Wollongong, NSW 2522, Australia

2 Department of Foundations of Economic Analysis I, Institute of Public Economics, University of the Basque Country, Avenida Lehendakari Aguirre 83, 48015 Bilbao, Spain 


\section{Introduction}

A widely discussed topic in environmental economics is the eventual existence of the socalled environmental Kuznets curve (EKC), which hypothesizes an inverted-U relationship between environmental degradation (i.e., pollution) and economic development (i.e., per capita income). Such a hump-shaped relationship emphasizes that in the earliest stages of development income and pollution go hand in hand, whereas in the following stages income keeps increasing while pollution drops. Thus, its overall graphical representation in the income-pollution plane first rises and then falls, resembling an inverted-U. In the proceeding of this paper, we refer to the former portion of the curve as the "rising arm" and to the latter portion as the "falling arm" of the EKC. After the seminal work of Grossman and Krueger (1991), the eventual occurrence of an EKC has been extensively studied from an empirical point of view, and in this context the analysis has been extended to various measures of environmental degradation, countries and periods (see Dinda 2004; Carson 2010, for recent reviews of these works). This empirical literature offers a mixed picture: even though for many pollutants or other single environmental quality indicators (such as sulfur dioxide concentrations) the inverted-U provides the best fit, for several others (such as carbon emissions) the relationship may remain linear or even become $\mathrm{N}$-shaped. The theoretical approach to the analysis of the income-pollution relationship includes a more modest but still fruitful branch of the literature trying to strengthen the connection between economic theory and observed empirical regularities. Three main types of explanations have been advanced by the theoretical literature: (i) those related to the income elasticity of demand for environmental quality, (ii) those related to the presence of increasing returns in abatement technology, and (iii) those related to the structural change that accompanies growth (see Copeland and Taylor 2004; Brock and Taylor 2005; Kijima et al. 2010 for extensive reviews of theoretical models). The first two of these three possible explanations of EKCs, namely those associated to the income elasticity of demand and the increasing returns in abatement technology, have already been exhaustively analyzed from a theoretical point of view. ${ }^{1}$ However, the last potential cause, namely the change in the structure of the economy associated to economic growth, has been very seldom considered from a theoretical perspective. Thus, the aim of this paper is to shed some light on this latter channel through which an inverted-U shaped income-pollution relationship might occur.

The structural change hypothesis proposes that economic development leads to a change in the structure of economic activity which shifts the economic production system from high polluting industry to low polluting services. Specifically, it conjectures that firstly the economic production system shifts from low polluting agriculture to high polluting industry and eventually shifts again to low polluting services. As Panayotou et al. (2000) clearly summarizes: "At low levels of development, both the quantity and the intensity of environmental degradation are limited to the impacts of subsistence economic activity on the resource base and limited quantities of biodegradable wastes. As agriculture and resource extraction intensity increase and industrialization takes off, [...] structural change towards information-based industries and services can result in a decline in environmental degradation". Previous works on structural changes and economic performance have been either empirical (Rowthorn and Ramaswamy 1997; Saeger 1997) or relied upon unbalanced growth (Baumol 1967; Pasinetti

\footnotetext{
1 John and Pecchenino (1994), Lopez (1994) and McConnell (1997) constitute some early examples of theoretical studies that show that the inverted-U shape of the income-pollution relationship may reflect changes in the demand for environmental quality as income rises. Selden and Song (1995), Stokey (1998) and Andreoni and Levinson (2001) investigate how different production or abatement technologies can lead to and EKC pollution profile.
} 
1981; Echevarria 1997; Laitner 2000; Kongsamut et al. 2001) models, while those relating structural changes and the environment have been mainly empirical (de Bruyn 1997; Panayotou et al. 2000; Suri and Chapman 1998) or relying upon general equilibrium (de Groot 2003; Pasche 2002) models. In this paper we instead try to incorporate the dynamics of structural change into the balanced growth models commonly used in the macroeconomics and growth literature. Specifically, we develop a standard balanced growth path (BGP) analysis to study the dynamics of income, structural change and pollution, contributing to the almost nonexistent theoretical literature on the role of structural change in explaining EKC-type regularities. ${ }^{2}$ We concentrate on economies that are already in an industrialized stage, thus we do not consider the first phase of the structural change involving a movement away from agriculture, and we focus only on the shift from polluting manufactures to non-polluting services. ${ }^{3}$

Specifically, we wish to understand whether and under which conditions a hump-shaped EKC may arise due to some form of structural change. Structural change might occur because of international trade liberalization and the imposition of carbon taxes, which may have a direct effect on the composition of industries (Ederington et al. 2004; Pezzey 1992). We do not try to investigate how and why a structural change might occur but we simply assume that at a certain stage of the development process it does occur (the structural change is exogenous in our framework), but try to understand whether such a variation in the economic productive sector is enough to explain a bell-shaped income-pollution path. In particular, we focus on forms of structural change which can be described merely as sectoral shifts from the manufacturing to the services sector; this is consistent with empirical evidence from developed economies which have recently experienced a substantial decline in manufacturing's share of GDP and a simultaneous rise in the share of services (Nickell et al. 2008), a phenomenon often referred to as deindustrialization. ${ }^{4}$ Understanding what are the implications of such a recent trend in the development process of advanced economies for the income-pollution relationship might be important to clarify the actual role of economic policies in promoting sustainable growth.

The paper is organized as follows. In Sect. 2 we briefly review the empirical literature on the EKC and discuss the role that structural change might play in shaping the relationship between income and pollution. We also provide some empirical support, based on decompo-

2 To the best of our knowledge, Pasche (2002), de Groot (2003) and Cherniwchan (2012) are the three only authors that, relying on general equilibrium models, explore from a theoretical perspective the conditions under which structural change may lead to an inverted-U shaped income-pollution relationship. Note that our approach, since relying on BGP outcomes, is substantially different from the first two papers; our goals is instead quite different from Cherniwchan's (2012) who focus on the effects of industrialization while we focus on deindustrialization. Other related works, even if with goals substantially different from ours, are Kongsamut et al. (2001) and André and Smulders (2014). Kongsamut et al. (2001) analyze an economic growth model, focusing on what they refer to as a "generalized balanced growth path" equilibrium, in which sectoral growth rates and employment shares are time varying; in their analysis, however, environmental implications are not considered at all. André and Smulders (2014) develop a model of directed technical change to replicate the dynamics of factor shares and prices in a context of non-renewable resource and energy use.

3 See Cherniwchan (2012) for an analysis of the impact of industrialization (that is the initial phase of structural change) on growth and environment, showing that (under certain conditions) a shift from a agriculture to industry may generate a bell-shaped EKC during the transition to the BGP. Differently from Cherniwchan (2012), our interest is on the impact of deindustrialization (and specifically, of tertiarization) rather than industrialization on the income and pollution relationship.

4 Note that, especially for meeting empirical goals, deindustrialization is usually defined as a decline in the share of manufacturing in total employment, rather than in total GDP (Saeger 1997). Its impacts on the development process of industrialized economies have been widely discussed in the literature; see, in particular, Rowthorn and Ramaswamy (1997), who show that deindustrialization is not a negative phenomenon but the natural consequence of the industrial dynamism in developed economies. 
sition analysis, to the fact that changes in the structure of the economy have been responsible to a large extent for the reduction of the carbon emission intensity of European economies in the past two decades. In Sect. 3 we introduce a simple two-sector (manufacturing and services) growth model where we allow for the presence of both environmental and production externalities other than complementarity between services and manufacturing capital investments. The model will then be used to study whether any of these elements plays a crucial role in determining the shape of the pollution-income relationship. Section 4 focuses on its steady-state outcome, that is the BGP equilibrium, and derives some theoretical results that are also supported by numerical simulations. We show that along the BGP equilibrium an inverted U-shaped EKC may arise because of structural changes, but whether this is the case or not it crucially depends upon the magnitude of a production externality parameter. Specifically, we characterize some sufficient conditions allowing the emissions-income relationship to be bell-shaped for almost all the possible configurations of the direction of technological progressiveness and the degree of abundance of the stock of services. Moreover, we show that the negative relationship between income and pollution that is hypothesized to occur once some critical level of development is achieved can only be a transitory phenomenon. This means that in the long run rising incomes will still be associated with rising pollution, generating overall an N-shaped pattern. Section 5 presents concluding remarks and highlights directions for future research. "Appendix 1" derives the BGP equilibrium and "Appendix 2" discusses an extension of the model.

\section{Structural Change and the Income-Pollution Relationship}

The interest of both policymakers and researchers in examining the link between per capita income and pollution started in the early 1990s has been originally stimulated by a question about the environmental impacts of trade liberalization in North America. It has been feared that freer trade and direct investment flows between the US and Mexico might aggravate pollution problems in the latter country due to its weak regulatory infrastructure, and might also undercut regulatory standards in the US (National Wildlife Federation 1990). To test this conjecture, Grossman and Krueger (1991) examine the empirical relationship between air quality measures and per capita income in a cross section of countries for different years. They conclude that economic growth tends to alleviate pollution problems once a country's per capita income reaches $\$ 4000-5000$ (USD 1985), coincidentally the per capita income level in Mexico at that time. Since their seminal work, a huge body of empirical works has proliferated in order to analyze the relationship between income and environmental quality. The initial reaction to Grossman and Krueger (1991) has led to a series of studies aiming to retest their empirical findings either incorporating other environmental degradation indicators or improving the econometric techniques. Thus, Shafik and Bandyopadhyay (1992) find that the lack of clean water and the lack of urban sanitation decline uniformly with increasing income and over time, that local air pollution conforms to the EKC hypothesis and that both municipal waste and carbon emissions per capita increase with rising income. Selden and Song (1994) estimate EKCs for $\mathrm{SO}_{2}, \mathrm{NO}_{x}, \mathrm{SPM}$ and $\mathrm{CO}$ emission series. Holtz-Eakin and Selden (1995) find that $\mathrm{CO}_{2}$ emissions increase over any possible income range for a rich panel of country for the years 1951-1986. Others find an N-shaped relationship (Friedl and Getzner 2003; Martínez-Zarzoso and Bengoechea-Morancho 2004), which suggests that de-linking environmental degradation from economic growth might be only temporary (He and Richard 2010). 
Since this empirical literature offers a mixed picture on the nature of the income and pollution relationship, many researchers claim to be skeptical about the existence of a simple and predictable relationship between pollution and per capita income (Arrow et al. 1995; Stern 2004; Kaika and Zervas 2013). Thus, some have suggested the necessity to move beyond reduced-form specifications of the income-pollution relationship and to consider other methodologies (both empirical and theoretical methods of analysis) that might shed some light on the main drivers of such a relationship. Grossman (1995) introduces decomposition analysis as a complementary empirical tool to reduced-form regressions in order to study the underlying forces (he distinguishes the scale, composition and technical effects) that shape the income-pollution relationship. de Bruyn (1997) argues that decomposition analysis, being a purely descriptive technique, would provide only limited insights into the mechanisms that could explain the decline of pollution associated with increases in income. As Stern et al. (1996) suggest, "if econometric studies are to provide a basis for projections of future trends, they will need to take the form of structural models, rather than reduced form equations of the EKC type". However, de Bruyn (1997) also recognizes that structural models are very data intensive and some of the equations from the structural model have not been adequately specified in theoretical contributions. Consequently, he concludes that decomposition analysis is an attractive tool for disentangling the different underlying forces and empirically determining the influence of each of them.

Structural change is a well-known (and at the same time striking) empirical regularity of the growth process. Kuznets (1966), Maddison (1980) and Ngai and Pissarides (2004), for example, provide ample empirical evidence of the structural changes that accompany growth. All this empirical evidence implies what Kongsamut et al. (2001) refer to as the "Kuznets (stylized) facts": growth in per capita income tends to be accompanied by a rise in services and a decline in the agricultural sector, both in terms of labor employment and relative weight in GDP. Schettkat and Yocarini (2006) review the three types of explanations that have been put forward to explain such structural changes: (i) shifts in the structure of final demand from goods to services; (ii) changes in the inter-industry division of labor, favoring specialized service activities to rise; or (iii) inter-industry productivity differentials. The structural change hypothesis is strongly linked to the "Kuznets facts", since it proposes that economic development leads to a structural change which shifts the economic production system from low polluting agriculture to pollution intensive industry and eventually shifts again to low polluting services (Panayotou 1993). There have been some empirical efforts to test whether structural change affects the income-pollution pattern, trying eventually to capture its influence. Thus, some authors have included in their reduced-form regressions a variable representing the structure of the economy ${ }^{5}$ (for example, Suri and Chapman 1998; Hettige et al. 2000, find that a higher share of industry in total GDP is associated with higher environmental pressure). Others have used decomposition analysis to measure the influence of structural change in reducing the pollution intensity of economic activity (for example, de Bruyn 1997; Weber 2009). Here the results are mixed. Whereas de Bruyn (1997) finds that structural change is much less important than technological change in explaining the reduction of $\mathrm{SO}_{2}$ emissions in the Netherlands and West Germany during the 1980s, Weber (2009) discovers that changes in the structure of the economy explain the decline in total energy intensity in the United States between 1997 and 2002 more than the increased energy efficiency.

\footnotetext{
5 Note that, as already stressed by some researchers (de Bruyn 1997), expanding the reduced-form model with explanatory variables may introduce serious multicollinearity problems.
} 
Table 1 Variables used in decomposition analysis

\begin{tabular}{ll}
\hline Variable & Definition \\
\hline$I=\frac{C}{Y}$ & Carbon emissions intensity \\
$C_{i}=\sum_{j} C_{i j}$ & $\begin{array}{c}\text { Total carbon emissions of all energy sources } \\
\text { consumed in sector } i\end{array}$ \\
$C_{i j}$ & $\begin{array}{c}\text { Carbon emissions of energy source } j \\
\text { consumed in sector } i\end{array}$ \\
$E_{i}=\sum_{j} E_{i j}$ & Total energy consumption in sector $i$ \\
$E_{i j}$ & The amount of energy from source $j$ \\
$Y_{i}$ & consumed in sector $i$ \\
$C=\sum_{i} C_{i}$ & Gross value added of sector $i$ \\
$Y=\sum_{i} Y_{i}$ & Aggregate carbon emissions \\
& Aggregate gross value added
\end{tabular}

It is beyond the scope of this paper to discuss and compare these studies. We just mention that there are several important factors (such as the different nature of the considered environmental problems, the influence of external shocks like the oil crisis of 1973 and 1979 and even the level of sectoral disaggregation of input data) that may help understanding the differences in the relative importance of structural and technological changes as drivers of variations in the pollution intensity of economic activity. Instead, what we want to stress here is that structural change is by no means a negligible driver of the pollution-income relationship. In order to do so, we briefly carry out a quantification of the role played by structural change in reducing carbon intensity in the EU-25 between 1995 and 2009. We use data from the world input-output database (Timmer 2012), which is disaggregated for each country in 35 productive sectors and 25 energy sources. In Table 1 we define the variables for each country that are used in this decomposition analysis:

According to the notation introduced above, the carbon emissions intensity from a country can be written as:

$$
I=\frac{C}{Y}=\frac{\sum_{i, j} C_{i j}}{Y}=\sum_{i, j} \frac{C_{i j}}{E_{i j}} \frac{E_{i j}}{E_{i}} \frac{E_{i}}{Y_{i}} \frac{Y_{i}}{Y}=\sum_{i, j} f_{i j} m_{i j} e_{i} s_{i}
$$

where $f_{i j}$ is the carbon emissions coefficient for energy source $j$ in sector $i, m_{i j}$ is the consumption share of energy source $j$ in sector $i, e_{i}$ is the energy intensity of sector $i$ and $s_{i}$ is the share of sector $i$ in aggregate gross value added. Note that, for the sake of simplicity, we have not included time subscripts in the definition of the variables. However, these variables change over time. Thus, if we differentiate both sides of Eq. (1) with respect to time, we obtain:

$$
\dot{I}=\sum_{i j} m_{i j} e_{i} s_{i} \dot{f}_{i j}+\sum_{i j} f_{i j} e_{i} s_{i} \dot{m}_{i j}+\sum_{i j} f_{i j} m_{i j} s_{i} \dot{e}_{i}+\sum_{i j} f_{i j} m_{i j} e_{i} \dot{s}_{i}
$$

Equation (2) shows that an observed change in carbon emissions intensity $(\dot{I})$ can be decomposed into four effects: (i) an effect driven by changes in carbon emissions coefficients $\left(\sum_{i j} m_{i j} e_{i} s_{i} \dot{f}_{i j}\right)$, (ii) an effect driven by changes in the mix of energy sources $\left(\sum_{i j} f_{i j} e_{i} s_{i} \dot{m}_{i j}\right)$, (iii) an effect driven by changes in energy intensity $\left(\sum_{i j} f_{i j} m_{i j} s_{i} \dot{e}_{i}\right)$, and (iv) an effect driven by changes in the structure of the economy $\left(\sum_{i j} f_{i j} m_{i j} e_{i} \dot{s}_{i}\right)$. We will refer to them as the "emission factor effect" (emf), the "energy mix effect" (mix), the "energy intensity effect" (int) and the "structural effect" (str), respectively. 
Table 2 Formulae to apply LMDI-based decomposition

\begin{tabular}{lll}
\hline Effect & Representation & Formula \\
\hline Emissions factor & $\Delta_{e m f}$ & $\Delta_{e m f}=\sum_{i, j} \frac{f_{i j}^{T} m_{i j}^{T} e_{i}^{T} s_{i}^{T}-f_{i j}^{0} m_{i j}^{0} e_{i}^{0} s_{i}^{0}}{\ln \left(f_{i j}^{T} m_{i j}^{T} e_{i}^{T} s_{i}^{T}\right)-\ln \left(f_{i j}^{0} m_{i j}^{0} e_{i}^{0} s_{i}^{0}\right)} \ln \left(\frac{f_{i j}^{T}}{f_{i j}^{0}}\right)$ \\
Energy mix & $\Delta_{m i x}$ & $\Delta_{e m f}=\sum_{i, j} \frac{f_{i j}^{T} m_{i j}^{T} e_{i}^{T} s_{i}^{T}-f_{i j}^{0} m_{i j}^{0} e_{i}^{0} s_{i}^{0}}{\ln \left(f_{i j}^{T} m_{i j}^{T} e_{i}^{T} s_{i}^{T}\right)-\ln \left(f_{i j}^{0} m_{i j}^{0} e_{i}^{0} s_{i}^{0}\right)} \ln \left(\frac{m_{i j}^{T}}{m_{i j}^{0}}\right)$ \\
Energy intensity & $\Delta_{i n t}$ & $\Delta_{e m f}=\sum_{i, j} \frac{f_{i j}^{T} m_{i j}^{T} e_{i}^{T} s_{i}^{T}-f_{i j}^{0} m_{i j}^{0} e_{i}^{0} s_{i}^{0}}{\ln \left(f_{i j}^{T} m_{i j}^{T} e_{i}^{T} s_{i}^{T}\right)-\ln \left(f_{i j}^{0} m_{i j}^{0} e_{i}^{0} s_{i}^{0}\right)} \ln \left(\frac{e_{i}^{T}}{e_{i}^{0}}\right)$ \\
Structural & $\Delta_{s t r}$ & $\Delta_{e m f}=\sum_{i, j} \frac{f_{i j}^{T} m_{i j}^{T} e_{i}^{T} s_{i}^{T}-f_{i j}^{0} m_{i j}^{0} e_{i}^{0} s_{i}^{0}}{\ln \left(f_{i j}^{T} m_{i j}^{T} e_{i}^{T} s_{i}^{T}\right)-\ln \left(f_{i j}^{0} m_{i j}^{0} e_{i}^{0} s_{i}^{0}\right)} \ln \left(\frac{s_{i}^{T}}{s_{i}^{0}}\right)$ \\
Total & $\Delta_{t o t}$ & $\Delta_{t o t}=I_{T}-I_{0}=\Delta_{e m f}+\Delta_{m i x}+\Delta_{i n t}+\Delta_{s t r}$
\end{tabular}

Index decomposition analysis (IDA) is used to provide a discrete-time decomposition approximation to Eq. (2). A wide range of methods has been established under the umbrella of IDA but the log mean divisia index (LMDI) has increasingly become the preferred approach (see Ang 2004). Following Ang and Liu (2001), the formulae used to calculate each of the effects are presented in Table 2.

From the decomposition results presented in Fig. 1 and despite the fact that the heterogeneity across countries is high, we can assert that structural change is an important driver of the carbon intensity reduction experienced by European countries between 1995 and 2009 (especially in Romania, Sweden, Slovenia, Hungary, Slovak Republic, Czech Republic, Germany and Estonia where structural change is responsible for more than $50 \%$ of the change in carbon intensity). Note that, even if from a slightly different perspective (focusing on energy intensity instead of carbon intensity), other studies such as Duro et al. (2010) and Mulder et al. (2014) support our conclusion that shifts towards a service economy have contributed greatly to lower the environmental pressure of economic activity. Specifically, Duro et al. (2010) find that differences in sectoral structures account for almost half of energy intensity inequality between OECD countries in 2005. Mulder et al. (2014) also find that the shift towards services in OECD countries has contributed to reduce energy intensity even though the service sector shows a very modest decrease in energy intensity in comparison to the energy efficiency improvements in the manufacturing sector. Thus, given this empirical evidence it is surprising that the structural change argument, being a very intuitive notion and one of the most commonly mentioned explanations for the EKC, has hardly been explored in the theoretical literature. In the next section we develop a simple model that allows us to bridge such a gap.

\section{The Model}

We consider a two-sector endogenous growth model á-la Uzawa-Lucas (1988), driven by services accumulation. ${ }^{6}$ The economy is composed only by households and firms. Households receive the rental rates of the two forms of capital they own (manufacturing and services

6 We assume that the amount of services produced in the economy is a stock variable, thus services represent a form of capital. In the paper we alternatively use the terms services or services capital to refer to such a stock variable. By interpreting services merely as education, understanding why services can be accumulated is 


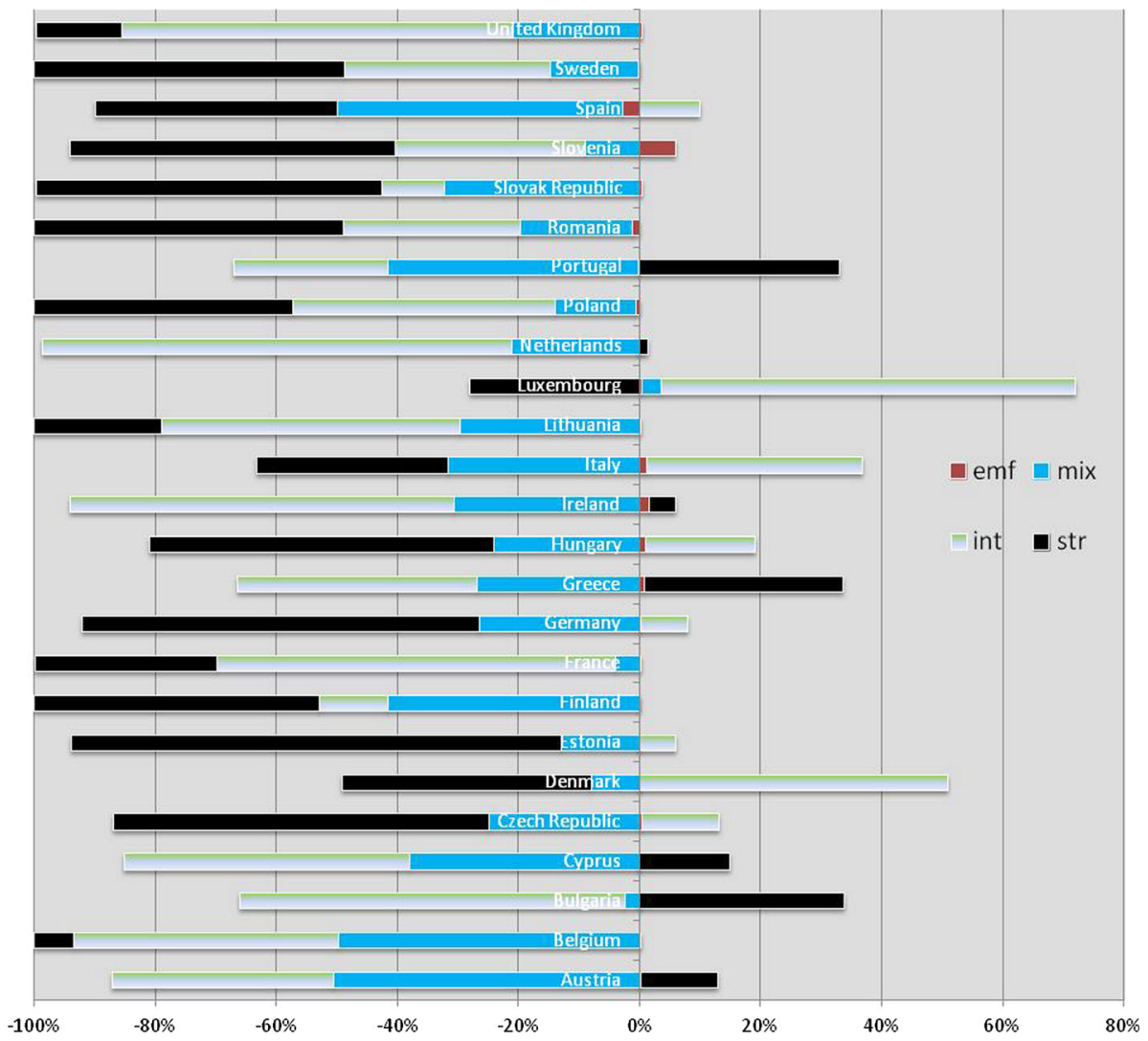

Fig. 1 Decomposition of carbon intensity changes in EU25 countries (1995-2009) (Source Our own calculations)

capital), purchase consumption goods and choose how much to save and how much to invest in services accumulation. Population coincides with the available number of workers (full employment) and is constant (normalized to 1 for the sake of simplicity), thus there is no difference between per capita and aggregate variables. Firms produce competitively the final consumption good, compensating each input according to its own marginal product. The production process generates pollution which negatively affects households' wellbeing through the utility channel. Other than such an environmental externality, a productive externality crucially affects the production of the final consumption good. Since firms and households do not internalize such production and environmental externalities, they take the level of pollution and total factor productivity (TFP) as given. ${ }^{7}$

\section{Footnote 6 continued}

straightforward. However, we do not restrict our analysis to the case of human capital and we refer to services in general.

7 Apart from the environmental implications, similar multi-sector models have been frequently analyzed in the growth literature (Lucas 1998; Uzawa 1965); see, among others, Sequeira and Reis (2006) and La Torre and Marsiglio (2010) who consider the interactions between human capital and technological progress, and Bucci and Segre (2011) analyzing the links between human and cultural capital accumulation. 
The final consumption good, $y_{t}$, is produced in a competitive sector according to the following Cobb-Douglas production function:

$$
y_{t}=a\left(u_{t} x_{t}\right)^{\alpha} k_{t}^{1-\alpha}
$$

combining manufacturing capital, $k_{t}$, and the share of services devoted to the production of goods, $u_{t} x_{t}$, where $x_{t}$ denotes services and $u_{t} \in[0,1]$. The terms $\alpha$ and $1-\alpha$ represent the services and manufacturing shares of aggregate production, respectively, whereas $a$ is a scale factor measuring the TFP. Even if this latter element is taken as a constant by each single firm producing consumption goods, we assume that it depends on some function of the relative intensity of the two forms of capital at the economy-wide level, and in particular, as in Bucci and Segre (2011), it depends nonlinearly on the ratio of the manufacturing and services capital stock, $\frac{k_{t}}{x_{t}}$, as follows:

$$
a=\left(\frac{k_{t}}{x_{t}}\right)^{\phi}
$$

where $\phi \in \mathbb{R}$ measures the intensity of the production externality affecting the final good sector. Such a production externality creates a gap between the returns to the production factors, as perceived at private (when the externality is not internalized) and social (when it is internalized) levels. ${ }^{8}$ Specifically, when $\phi>0$ the privately perceived returns to service (manufacturing) capital are higher (lower) than the social returns; in turn, when $\phi<0$ the privately perceived returns to service (manufacturing) capital are lower (higher) than the social returns. This externality can be interpreted as a simple way to account for the knowledge spillovers of research and development $(R \& D)$ cooperation and therefore its sign and intensity can be linked to the technological progressiveness ${ }^{9}$ of both manufacturing and service sectors in our model. Indeed, even if technological progress is generally interpreted as a wide concept broadly involving the whole economy, in reality its effects may vary from industry to industry and from sector to sector (Maclaurin 1954). This implies that the way in which technological advances impact on economic activities (measured by $a$ in our model) depends upon which of the two sectors is more technologically progressive than the other. Thus, the $\phi>0$ case can be interpreted as a situation where manufacturing is relatively more technologically progressive than services, since knowledge spillovers increase the contribution of manufacturing in the production of final output and at the same time reduce the contribution of services; conversely, the $\phi<0$ case can be interpreted just in the opposite sense, since knowledge spillovers reduce the contribution of manufacturing in final output and increase the contribution of services. Note that, despite the direction of technological progressiveness determining which sector benefits more from knowledge spillovers, the overall impact on output of the externality depends on the degree of abundance of the stock of services in the economy. When the

8 Indeed, the production function as perceived at social level reads as $\tilde{y}_{t}=u_{t}^{\alpha} x_{t}^{\alpha-\phi} k_{t}^{1-\alpha+\phi}$, which implies that the returns to the production factors at social level, $\widetilde{r}_{t}$ and $\widetilde{p}_{t}$, are different from those at private level $r_{t}$ and $p_{t}$, as determined in (6) and (7), respectively.

9 The concept of technological progressiveness has been introduced by Maclaurin (1954) to refer to the use of science and technology and the capacity to produce or adopt new products or processes. By comparing the experience of thirteen American industries, Maclaurin (1954) states that since the role of technology necessarily changes from one to the next, every industry is characterized by a different degree of technological progressiveness, determining which will tend to languish over time and which not. Nordhaus (2008) uses a complete set of industry accounts for the period 1948-2001 in the US and concludes that "industries that are technologically stagnant tend to have slower growth in real output than do the technologically dynamic ones, with a one percentage-point lower productivity growth being associated with a three-quarters percentage-point lower real output growth". 
amount of services is already abundant $(\phi>\alpha)$ an increase in the stock of services reduces its (social) marginal productivity in final production, thus additional increases in the stock of services cannot further increase output; when the amount of services is scarce in the economy $(\phi<\alpha)$ an increase in the stock of services increases its (social) marginal productivity in the production of consumable goods. Note that when $\phi=\alpha$ the (social) production function will not depend upon services, thus such a case is trivial and not interesting for our goals of assessing the economic impact of a sectoral shift (from manufacturing to services). Therefore, in the proceeding of the paper we restrict our analysis to the most interesting situations in which $\phi \neq \alpha$.

Production activities generate pollution, $z_{t}$, which is merely a negative environmental externality (affecting households' preferences), and which is assumed to be a flow variable and to depend on the manufacturing capital intensity in the technical process producing final output:

$$
z_{t}=\eta k_{t}^{\psi(1-\alpha)}
$$

where $\eta, \psi>0$ are parameters measuring the degree of environmental efficiency. Equation (5) represents a situation in which the amount of services employed in final production is totally pollution-free. ${ }^{10}$ Such a specification allows us to emphasize the intuition underlying the structural change hypothesis, by focusing on a sectoral change from a polluting to a totally clean production factor. However, as we shall see in a while, even in such an optimistic framework a bell-shaped EKC may not arise. Since firms do not internalize the production and environmental externalities, maximization of instantaneous profits leads to:

$$
\begin{aligned}
& r_{t}=a \alpha\left(\frac{k_{t}}{u_{t} x_{t}}\right)^{1-\alpha} \\
& p_{t}=a(1-\alpha)\left(\frac{k_{t}}{u_{t} x_{t}}\right)^{-\alpha},
\end{aligned}
$$

where $r_{t}$ and $p_{t}$ denote the (private) marginal productivity of manufacturing and services in the production of final goods, respectively.

The representative household owns the factors of production, and tries to maximize its lifetime utility given the dynamic evolution of manufacturing and services capital. We assume that not consumed income is entirely used for manufacturing investment purposes. Thus the accumulation of manufacturing capital is given by:

$$
\dot{k}_{t}=y_{t}-c_{t},
$$

where $y_{t}$ denotes income and $c_{t}$ consumption. Since only a certain share of services is devoted to consumer goods production, $u_{t}$, the remaining portion, $1-u_{t}$, is used to produce new services. Services accumulate over time according to the following law of motion:

$$
\dot{x}_{t}=\theta\left(1-u_{t}\right) x_{t}+\varphi \gamma_{k} x_{t},
$$

\footnotetext{
10 A more realistic assumption on pollution would be the following: $z_{t}=\eta\left(u_{t} x_{t}\right)^{\psi_{1} \alpha} k_{t}^{\psi_{2}(1-\alpha)}$, which states that the pollution intensity of production factors is different. Note that by setting $\psi_{1}=0$ and $\psi_{2}=\psi$ we obtain our formulation which stresses the fact that one input (services) is a totally clean production factor. However, it is possible to show that adopting such an extended specification would not lead to qualitatively different results. Specifically, a conclusion very similar to what derived in Proposition 3 would still hold provided that $\psi_{2}>\psi_{1}$, which intuitively requires that the structural change moves production away from a relatively dirtier (manufacturing) towards a relatively cleaner sector (services). It thus seems more convenient to present our model in the simplest possible form. See "Appendix 2" for further details.
} 
where $\theta>0$ is the productivity of services employed in the production of new services and $\varphi \in(0,1)$ reflects the impact of the growth rate of manufacturing capital, $\gamma_{k} \equiv \frac{\dot{k}_{t}}{k_{t}}$, on the accumulation of services. The parameter $\varphi$ can be interpreted as a measure of the degree of complementarity between the two forms of capital investments. The household's lifetime utility is the infinite discounted ( $\rho$ is the pure rate of time preference) sum of instantaneous utilities, which depend on consumption and pollution. The instantaneous utility function is assumed to be separable in consumption and pollution and to take a constant elasticity of substitution form:

$$
u\left(c_{t}, z_{t}\right)=\frac{c_{t}^{1-\sigma}-1}{1-\sigma}-\beta \ln z_{t},
$$

where $\sigma>1$ is the inverse of the intertemporal elasticity of substitution in consumption and $\beta \geq 0$ measures the weight of pollution in household's preferences (denoting the green preferences parameter). Given initial conditions, $k_{0}>0$ and $x_{0}>0$, the representative household's problem can be summarized as:

$$
\begin{aligned}
\max _{c_{t}, u_{t}} \quad U & =\int_{0}^{\infty}\left(\frac{c_{t}^{1-\sigma}-1}{1-\sigma}-\beta \ln z_{t}\right) e^{-\rho t} d t \\
\text { s.t. } \quad \dot{k}_{t} & =r k_{t}+p u_{t} x_{t}-c_{t} \\
\dot{x}_{t} & =\theta\left(1-u_{t}\right) x_{t}+\varphi \gamma_{k} x_{t}
\end{aligned}
$$

\section{BGP Analysis}

In order to perform our analysis of the economic-environmental relationship, we focus on a BGP equilibrium along which the growth rate of all variables is constant. It is possible to show that along the BGP, both the economic and environmental variables grow at constant and positive rates.

Proposition 1 Assume $\theta>\rho$; along the BGP equilibrium the economic and pollution growth rates are respectively given by:

$$
\begin{aligned}
& \gamma \equiv \gamma_{c}=\gamma_{k}=\gamma_{x}=\gamma_{y}=\frac{\theta-\rho}{\sigma-\varphi}>0 \\
& \gamma_{z}=\psi(1-\alpha) \gamma>0,
\end{aligned}
$$

while the share of services allocated to final goods production is equal to:

$$
\bar{u}=\frac{\theta(\sigma-1)+\rho(1-\varphi)}{\theta(\sigma-\varphi)} \in(0,1)
$$

Proof See "Appendix 1".

The condition in Proposition 1, stating that the productivity of services into the production of new services is larger than the rate of time preference, ensures that the BGP equilibrium is well defined. Provided that such a condition is met, all economic variables grow at the same rate, $\gamma$, while environmental variables (i.e., pollution) grow at a different rate, $\gamma_{z}$, which can be equal to, higher or lower than $\gamma$ according to the size of $\psi(1-\alpha)$ (whether it is equal to, higher or lower than unity). Note that the BGP growth rates and the share of services devoted to the manufacturing sector are independent of the production externality $(\phi)$ and the green 
preference parameter $(\beta)$, while they are affected by the degree of complementarity between manufacturing and services investments $(\varphi)$.

Our main goal in this paper is to determine whether and under which (sufficient) conditions an EKC may be the result of structural changes. In particular, we focus on sectoral shifts, ${ }^{11}$ leading to a gradual and permanent reduction in the share of manufactures in total GDP (a drop in $1-\alpha$ ). This is consistent with recent empirical evidence showing that in advanced countries the manufacturing's share of GDP tends to decrease while the share of services tends to increase (Ederington et al. 2004; Nickell et al. 2008). Nickell et al. (2008) show that in the 1975-1995 period the reduction in the manufacturing share of GDP in Japan, UK and US has been substantial (about 5 percentage points), and such a reduction has been accompanied by an increase in the share of services. A possible explanation of such a decline in the manufacturing share is related to the pollution haven hypothesis stating that when economies become sufficiently rich they may spin-off pollution-intensive products to developing countries with lower environmental standards, either by buying dirty goods from abroad or by directly producing these goods in these countries (Mani and Wheeler 1998). Several factors may induce the search and development of pollution havens, and in particular international trade policies, environmental regulation and carbon taxes ${ }^{12}$ are thought to play an important role in this process. We do not enter into the details of why such a sectoral shift might occur, but we simply analyze what are its implications on the income-pollution relationship, provided that it does occur.

In order to understand what are the impacts of a sectoral shift on both the economy and the environment, note first that along the BGP both output and pollution increase and such a situation is associated with a positively sloped part of the EKC (the rising arm). In order for an inverted-U income-pollution relationship to occur we would need to observe also a negatively sloped part along which output keeps growing while pollution drops (the falling arm). Thus, in order to identify whether a hump-shaped EKC is likely to occur, we need to understand how income and pollution are related to factor shares. Specifically, a reduction in $1-\alpha$ should increase (or at least not decrease) $y$ and simultaneously decrease $z$ along a falling arm of the EKC. The following proposition summarizes how the shares of manufacturing and services are related to pollution and income.

Proposition 2 Along the BGP equilibrium, pollution is a monotonically increasing function of the manufacturing share of GDP, while the relationship between income and the manufacturing share of GDP depends upon the magnitude of $\phi$ (specifically, income will be a monotonically decreasing function of $1-\alpha$ if $\phi>\alpha$ or $\phi<\frac{\omega-\sqrt{\omega^{2}+4 \epsilon}}{2}$, where $\omega \equiv(1-\alpha) \ln \bar{u}+2 \alpha-1$ and $\epsilon \equiv \alpha(1-\alpha)$; otherwise it will be a non-monotonic function of $1-\alpha)$.

Proof From Eq. (5), it is straightforward to obtain $\frac{\partial z_{t}}{\partial(1-\alpha)}=\eta \psi k_{t}^{\psi(1-\alpha)} \ln k_{t}>0$. After some algebra (see Appendix 1), it is possible to write: $y_{t}=\bar{u}^{-\frac{\alpha}{\phi-\alpha}}\left(\frac{r}{1-\alpha}\right)^{\frac{1+\phi-\alpha}{\phi-\alpha}} x_{t}$, where $r=\frac{\theta \sigma-\varphi \rho}{\sigma-\varphi}$. Differentiating with respect to $1-\alpha$ yields: $\frac{\partial y_{t}}{\partial(1-\alpha)}=x_{t}\left(\frac{r}{1-\alpha}\right)^{\frac{1+\phi-\alpha}{\phi-\alpha}} \frac{\bar{u}^{-\frac{\alpha}{\phi-\alpha}}}{\phi-\alpha}\left[\frac{\phi \ln \bar{u}}{\phi-\alpha}\right.$ $\left.-\frac{1}{\phi-\alpha} \ln \left(\frac{r}{1-\alpha}\right)-\frac{1+\phi-\alpha}{1-\alpha}\right]$. Note that $\ln \bar{u}<0$ since $\bar{u} \in(0,1)$, while $\ln \left(\frac{r}{1-\alpha}\right)>0$ since

11 By relying on Grossman (1995) analysis, we focus only the composition effect as a possible determinant of changes in (aggregate) pollution (we do not allow for any scale or technique effects). Specifically, such a compositional change in final output is taken as exogenous in our framework.

12 Note that pollution havens are not only affected by environmental policies but can also affect the effectiveness of such policies. For example, Pezzey (1992) estimates that a $20 \%$ unilateral cut in the European Community's carbon-based energy consumption achieves only a $0.7 \%$ cut in world consumption. 
$r>1$ (due to the fact that $\theta>\rho$ ). Thus, it is clear that as long as $\phi>\alpha$, the term outside the square brackets is positive, while the term inside the brackets is negative, thus the sign of the derivative is negative. If $\phi<\alpha$ (and note that in this case $\phi$ can also be negative), the term outside the square brackets is negative, while that inside the brackets has an ambiguous sign, thus the sign of the derivative is ambiguous too; even in this case it is however possible to find a sufficient condition for the sign of this term to be positive (such that the derivative turns out to be negative), and specifically this happens whenever $\phi \in\left(-\infty, \Lambda_{1}\right] \cup\left[\Lambda_{2}, \infty\right)$ where $\Lambda_{1}=\frac{1}{2}\left[\omega-\sqrt{\omega^{2}+4 \epsilon}\right]<0$ and $\Lambda_{2}=\frac{1}{2}\left[\omega+\sqrt{\omega^{2}+4 \epsilon}\right]>0$, with $\omega \equiv(1-\alpha) \ln \bar{u}+2 \alpha-1$ and $\epsilon \equiv \alpha(1-\alpha)$. Since $\Lambda_{2}>\alpha$ the only relevant case is represented by $\phi \in\left(-\infty, \Lambda_{1}\right]$.

Proposition 2 shows that the relationship between pollution and the share of manufacturing is positive, while that between income and the share of manufacturing strictly depends on the size of $\phi$. Specifically, this is unambiguously negative only when the magnitude (in absolute value) of the production externality parameter $(\phi)$ is sufficiently large, and this is the unique case consistent with a falling arm of the EKC. Note however that these results do not take into account the fact that manufacturing and services capital do grow along the BGP; thus the overall impact of a structural change on both income and pollution depends on the relative magnitude of two different forces, which we refer to as the "sectoral shift effect" and the "factors accumulation effect". The former suggests that as the manufacturing share of GDP drops pollution tends to fall and income might fall if certain parametric conditions are met. The latter instead suggests that, independently of the reduction in the manufacturing share, along the BGP both manufacturing and services capital increase, and this tends to rise both pollution and income. Therefore the net impact of structural change depends on which effect dominates: in an earlier phase of structural change when the reduction in the share of manufacturing is small it is likely that the factors accumulation effect is larger such that pollution and income keep growing; in a later stage when the drop in the manufacturing share is more consistent it is likely that the sectoral shift effect dominates and thus both pollution and (eventually) income start to fall. As it will become more clear later from our numerical simulations, the existence of such two effects implies that the structural change affects the economic and environmental system with some delay: an eventual falling arm will be generated not as soon as the sectoral shift takes place but only after some time, namely whenever the sectoral shift effect is larger than the factors accumulation effect.

Despite the existence of such a delay, according to Proposition 2, along the BGP in order for a decrease in the manufacturing share to be associated to further increases in income the size of the production externality parameter needs to be large enough. This might happen in two alternative scenarios: whenever it is smaller than a certain value $\left(\frac{\omega-\sqrt{\omega^{2}+4 \epsilon}}{2}\right)$ or whenever it is larger than the share of services $(\alpha)$. This means that it is possible for a sectoral shift to generate a falling arm of the EKC both when manufacturing is relatively more technologically progressive than services $(\phi>0)$ and when services are relatively more technologically progressive than manufacturing $(\phi<0)$, since reductions in the manufacturing share will reduce pollution and simultaneously increase income. However, note that in both cases the production externality has to be strong enough. If it is not, that is, if $\frac{\omega-\sqrt{\omega^{2}+4 \epsilon}}{2}<\phi<\alpha$, these further increases in income may not occur and income could even fall as the manufacturing share decreases. Thus, it is straightforward to identify in which specific scenarios a sectoral shift can undoubtedly generate an inverted U-shaped income-pollution relationship.

Proposition 3 Along the BGP, a hump-shaped EKC path is consistent with a decrease in the manufacturing share (i.e., a drop in $1-\alpha$ ) in two alternative cases:

(i) whenever the production externality is small enough, that is $\phi<\frac{\omega-\sqrt{\omega^{2}+4 \epsilon}}{2}$; or 
(ii) whenever it is larger than the share of services, namely $\phi>\alpha$.

Proof The BGP is directly associated to a rising arm of the EKC since both income and pollution increase. From Proposition 2, it is clear that the sectoral shift can unambiguously induce a negative income-pollution relationship only when $\phi<\frac{\omega-\sqrt{\omega^{2}+4 \epsilon}}{2}$ or $\phi>\alpha$.

If the production externality parameter is sufficiently small $\left(\phi<\frac{\omega-\sqrt{\omega^{2}+4 \epsilon}}{2}\right)$ or sufficiently large $(\phi>\alpha)$ then a decrease in the manufacturing share will generate the falling arm of the EKC, thus leading to an inverted-U relationship between income and pollution. Such a bell-shaped income-pollution relationship may occur both whenever the stock of services is scarce $(\phi<0<\alpha)$ and whenever it is abundant $(\phi>\alpha)$. Note that the occurrence of such an EKC cannot be taken for granted, since when the production externality is neither too small nor too large $\left(\frac{\omega-\sqrt{\omega^{2}+4 \epsilon}}{2}<\phi<\alpha\right)$ a similar sectoral shift may lead to a completely different outcome. ${ }^{13}$ Note also that the presence of complementarity in manufacturing and services investments $(\varphi)$ and a green preference component in preferences $(\beta)$ are totally irrelevant for the result in Proposition 3 to hold. Indeed, the only element needed for an EKC to arise as a consequence of deindustrialization is that the absolute value of the parameter measuring the strength of the production externality $(|\phi|)$ is sufficiently large.

But, what is the intuition behind this result? Let us considered first a situation characterized by a "large" negative value of $\phi$, which, as we mentioned above, may be representing an economy where services are relatively more technologically progressive than manufacturing. In this situation knowledge/technological spillovers will likely make the feasible productivity of services grow faster than manufacturing's. If the production externality is strong enough the overall growth of productivity of the service sector together with its exogenous increase due to structural change, will sustain economic growth. Let us now consider a situation characterized by a "large" positive value of $\phi$, representing an economy in which manufacturing is relatively more technologically progressive than services. In this case, despite the fact that a shift towards services implies a drag on economic performance, the growth in the productivity of capital resulting from a strong production externality may more than compensate it and lead to income growth. With regard to the question on which of the two scenarios described above is more realistic, this is very difficult to answer. A majority of innovation efforts in the form of formal R\&D takes place in manufacturing industries. However, R\&D performances in services has made steady growth in certain types of services (especially those related to the information sector). The services sector consists of a very disparate group of subsectors, with varying productivity performance. Maroto-Sánchez and Cuadrado-Roura (2009) study the impact of tertiarization on overall productivity growth using a sample of 37 OECD countries in the period between 1980 and 2005 and demonstrate that, contrary to what conventional theories suggest, several tertiary activities (basically they refer to market services) have shown dynamic productivity growth rates. Another important feature of innovation in the service sector is that, in contrast to the manufacturing sector, it draws less on in-house knowledge creation and, therefore, relies more on cluster formation fostering knowledge transfers and spillowers (Uppenberg and Strauss 2010).

In line with the results of Pasche (2002), Proposition 3 suggests also that the inverted-U relationship between income and pollution can only be a transitory phenomenon. This is due to the fact that since the share of manufacturing is actually a share (it has to lie between 0 and 1 ), the reduction in $1-\alpha$, representing the structural change affecting the overall economy,

13 This result may explain why some empirical studies support the structural change hypothesis (Suri and Chapman 1998) while others do not (de Bruyn 1997). 
cannot continue indefinitely. Moreover, as already mentioned above, as the manufacturing share of GDP decreases, the services share, $\alpha$, has to increase. This in turn means that, especially in the case (ii) in Proposition 3, whenever the specialization in services continues the production externality parameter needs to be substantially large in order for the condition $\phi>\alpha$ to be met. Note that if $\phi<1$, the negative link between output and pollution may be broken well before the service (manufacturing) share reaches the unity (zero) level. In such a framework, the length of the transition due to structural changes is directly related to the size of the gap between $\phi$ and $\alpha$, and in particular the smaller the externality parameter the shorter the transitory period associated with a falling arm of the EKC. However, also in case (i), once the transition generated by the structural change is over, the economy will lie on its new BGP along which both income and pollution grow at positive constant rates, as in (14) and (15); note that the reduction in $1-\alpha$ leads to a reduction in $\gamma_{z}$, which however is still positive along the new BGP. Thus, a new rising arm will be generated, and along the BGP the overall relationship between income and pollution will show an $\mathrm{N}$-shaped pattern.

In order to graphically illustrate this result, we run a simple numerical simulation. Since $\varphi$ and $\beta$ do not play any crucial role for our results we set their values equal to zero, and we choose parameter values consistent with a long run growth rate of $3 \%$ and satisfying the conditions in Proposition 3. Since the absolute value of $\phi$ needs to be large enough we set it equal to -2 and 2 in order to represent the case (i) and (ii) in Proposition 3 respectively.

The manufacturing share is set to be equal to 0.5 and to reduce over time till it will reach a value of 0.33 consistent with estimates of the (physical) capital share in GDP in developed countries. The values of $\eta$ and $\psi$ are arbitrarily chosen since for any positive value the relationship between pollution and the manufacturing share is decreasing (Proposition 2). Specifically, we set $\beta=\varphi=0, \sigma=2, \rho=0.04, \theta=0.1, \eta=1, \psi=0.1,|\phi|=2$, along with $k_{0}=x_{0}=1$. Initially, the economy develops along its BGP equilibrium and pollution and income increase over time. Then a structural change occurs and the manufacturing share gradually decreases for a while (from 0.5 to 0.33 ); during this transitory situation income keeps increasing while the rate of growth of pollution decreases; specifically, the variation in pollution remains positive as long as the factors accumulation effect is larger than the sectoral shift effect, but after some time the sectoral shift effect dominates and it becomes negative (that is, pollution starts decreasing even if income and manufacturing capital keep rising). Once the transition is over (the manufacturing share stops dropping and stabilizes at 0.33 ), the economy restarts developing along its new BGP equilibrium; along such a path income still increases and pollution starts increasing again. Figure 2 shows that the stationary BGP equilibrium (rising arm) is interrupted by the sectoral shift for a while (falling arm), thus the relationship between pollution and income shows overall an $\mathrm{N}$-shaped pattern; Fig. $2 \mathrm{a}$ and $\mathrm{b}$ illustrate the case (i) and (ii) respectively. By changing the value of $\phi$ it is possible to show that the outcomes exemplified by our simulation are robust, provided that the conditions in Proposition 3 are met.

Note that the outcome illustrated through our simulations is not dependent upon the length of the sectoral change we considered. In Figure 2 we consider for simplicity the case in which structural change is temporary, that is, the share of manufacturing drops for a while and then stabilizes at a certain value. However, the picture does not change even if structural change is permanent, that is, the share of manufacturing keeps dropping until reaching zero. The case is illustrated in Fig. 3, which shows that a pattern similar to what we have just discussed does occur: as long as the manufacturing share decreases a negative income-pollution relationship arises however when this share approaches (but does not reach) zero the income-pollution 

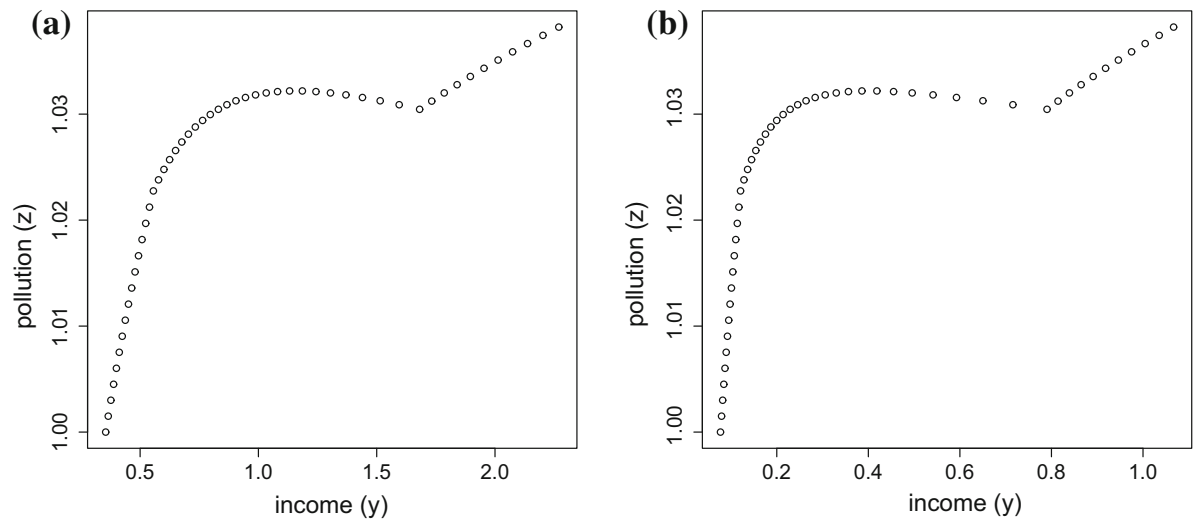

Fig. $2 \mathrm{~N}$-shaped EKC generated by a temporary sectorial shift associated to a reduction in the manufacturing share of GDP, along the BGP equilibrium. Value of the externality parameter set equal to -2 (a) and 2 (b). a Case (i): $\phi<\frac{\omega-\sqrt{\omega^{2}+4 \epsilon}}{2}$. b Case (ii): $\phi>\alpha$
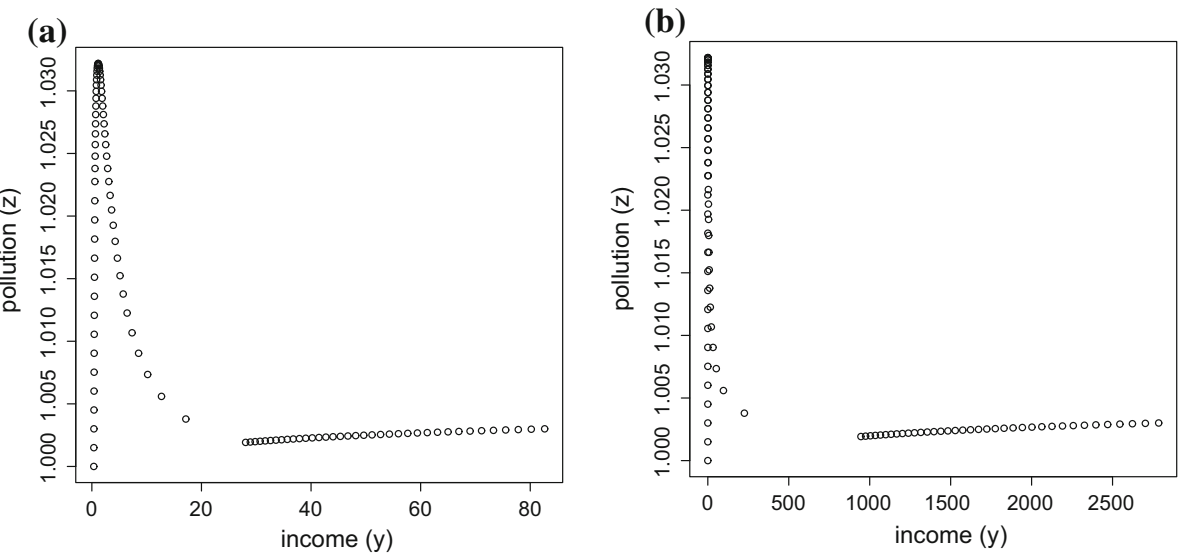

Fig. $3 \mathrm{~N}$-shaped EKC generated by a permanent sectorial shift associated to a reduction in the manufacturing share of GDP (converging to 0), along the BGP equilibrium. Value of the externality parameter set equal to -2 (a) and 2 (b). a Case (i): $\phi<\frac{\omega-\sqrt{\omega^{2}+4 \epsilon}}{2}$. b Case (ii): $\phi>\alpha$

relationship turns positive again. ${ }^{14}$ Also in this case it is possible to show that the outcomes exemplified in our simulation are robust, provided that the conditions in Proposition 3 are met. This suggests us that even by extending the analysis to a three or more sectors framework the results would not change substantially. With a larger number of sectors structural change might lead the economy to progressively switch from relatively dirtier to relatively cleaner

\footnotetext{
14 The only situation in which the new rising arm is not able to arise is related to a perpetual decrease in the manufacturing share. Indeed, in theory it may be possible that this share continues to fall at some constant rate forever (for example it may decrease by a certain percentage every period), such that it will approach zero asymptotically but without ever reaching zero. Provided that the manufacturing share keeps dropping forever then the EKC in finite time might be overall hump-shaped and the growth rate of pollution might converge to zero, meaning that a constant pollution level could be achieved asymptotically. However, a situation in which the manufacturing share approaches (even if asymptotically) zero is extremely unlikely in reality, thus the occurrence of an N-shaped EKC seems more plausible in the real world.
} 
sectors, and this might generate a falling arm; however, once the structural change is over (the shares of dirty sectors have approached zero), the economy will reach a new BGP generating a rising arm. Thus, the EKC will overall show an N-shaped pattern.

Such an N-shaped income-pollution relationship calls for a warning in the interpretation of the EKC. The potential existence of an inverted U-shaped relationship has often been considered as a positive signal of the fact that environmental problems will be automatically solved as income gets high enough ("although economic growth usually leads to environmental deterioration in the early stages of the process, in the end the best-and probably the only-way to attain a decent environment in most countries is to become rich"; Beckerman 1992). However, whenever the EKC shows an N-shaped pattern, as our model predicts, this type of conclusion is completely misleading. Indeed, it is true that at a certain stage of economic development for some reason (related for example to the exploitation of pollution havens) there may be a structural change leading to an inverse income-pollution relationship; however, such a situation will not last indefinitely and after a transitory period (it may not be possible to find poor countries able to serve as pollution havens forever) the nature of the income-pollution relationship may turn positive again, generating rising income and rising pollution.

The main implication of this result is that simply waiting for EKCs in developed and developing economies to turn down may be extremely costly in terms of environmental damages. It is therefore crucial that both developed and developing countries actively cooperate in order to find a solution to environmental and climate change problems that goes beyond simply promoting economic growth. Even though structural change (which may be induced by international trade policies and the search of pollution havens) may be an empirically valid argument to explain the falling arm of the $\mathrm{EKC}^{15}$ (Suri and Chapman 1998), structural change per se is not enough for maintaining over the long run such an inverse incomepollution relationship. Thus it is essential that the focus of policy interventions at global level is moved from international trade to other kinds of policies: specifically, clean technological progress and environmental preservation activities need to be fostered in order to address the development process indefinitely along a (sustainable) falling arm of the EKC. As Arrow et al. (1995) clearly state: "The solution to environmental degradation lies in [...] institutional reforms as would compel private users of environmental resources to take account of the social costs of their actions [...]. The inverted-U relation is evidence that this has happened in some cases. It does not constitute evidence that it will happen in all cases or that it will happen in time to avert the important and irreversible global consequences of growth".

\subsection{The Special Case $\phi=0$}

Proposition 3 states that the a hump-shaped EKC can occur as a result of a sectoral shift only if the value of the externality parameter falls in a specific range of values $\left(\phi<\frac{\omega-\sqrt{\omega^{2}+4 \epsilon}}{2}\right.$ or $\phi>\alpha$ ). Since such a range of values provides only sufficient conditions we cannot know a priori what the outcome would look like whenever the parameter falls outside this range $\left(\frac{\omega-\sqrt{\omega^{2}+4 \epsilon}}{2}<\phi<\alpha\right)$, and in particular, it may well be the case that an EKC-type path may not occur at all. Note that such a (narrow) range represents a situation in which the stock of services is scarce and, independently of the direction of technological progressiveness, the effects of the production externality are small. In order to shed some more light on this, we

15 In particular, Suri and Chapman (1998) show that "exports of manufactured goods by industrialized countries has thus been an important factor in generating the upward sloping portion of the EKC and imports by industrialized countries have contributed to the downward slope". 
now briefly analyze a specific case of our model, that is the situation in which there is no production externality $(\phi=0)$. In such a case it is possible to derive a simple condition to ensure that income increases whenever the manufacturing share of GDP falls, thus generating a bell-shaped EKC.

Proposition 4 Along the BGP, if there is no production externality (i.e., $\phi=0$ ) a humpshaped EKC path is consistent with a decrease in the manufacturing share (a drop in $1-\alpha$ ) whenever the $\xi \equiv \ln \left(\frac{r}{1-\alpha}\right)-\alpha>0$.

Proof The result directly follows from the fact that in the case $\phi=0$, the relationship between income and the manufacturing share of GDP is determined by the sign of the following derivative: $\frac{\partial y_{t}}{\partial(1-\alpha)}=-x_{t}\left(\frac{r}{1-\alpha}\right)^{-\frac{1-\alpha}{\alpha}} \frac{\bar{u}}{\alpha}\left[\frac{1}{\alpha} \ln \left(\frac{r}{1-\alpha}\right)-1\right]$. Such a derivative is negative whenever the term inside the brackets is positive, which happens whenever $\xi \equiv \ln \left(\frac{r}{1-\alpha}\right)-\alpha>0$.

Whenever the condition $\xi>0$ is met, then a falling arm will be generated by structural change consistently with the EKC hypothesis. When it is not, a rising arm will persist even during the transition associated with structural change. Whether such a condition is met or not clearly depends on the value of the manufacturing share of GDP: $\xi$ is a decreasing function of $\alpha$; thus, during the transition along which the share of services increases, $\xi$ will become larger and larger and therefore the condition is more likely to be met; however, for smaller values of $\alpha$ the condition very unlikely will be met. In this framework with no production externality, the impact of structural change in our economic-environmental system can be briefly summarized as follows: along the original BGP both income and pollution increase; then a sectoral shift occurs reducing (permanently) the manufacturing share of GDP and thus reducing pollution; given that at the earliest stages of the structural change the share of services is still small, the drop in the manufacturing share reduces also income $(\xi<0)$; at later stages, when the share of services is large, the continuing drop in the manufacturing share increases income $(\xi>0)$ and generates a falling arm; once the transition is over (the manufacturing share has converged to a positive value) the economy develops along a new BGP characterized by increases in both income and pollution. Figure 4 illustrates the dynamics of income, pollution and the income-pollution relationship for the same parameter values employed earlier (the only difference is the value of the externality parameter, since now $\phi=0$ ). While the dynamics of income and pollution are intuitive, identifying a clear pattern in the income-pollution relationship is not possible, since the condition in Proposition 4 is not met for the chosen parameter values (apart from the very last phase when the manufacturing share approaches zero). Note moreover that the presence

(a)

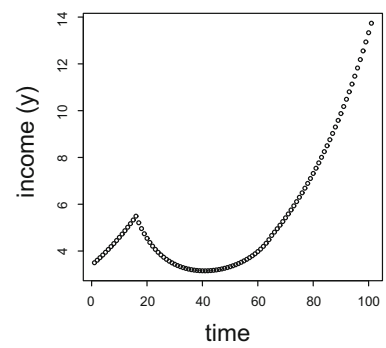

(b)

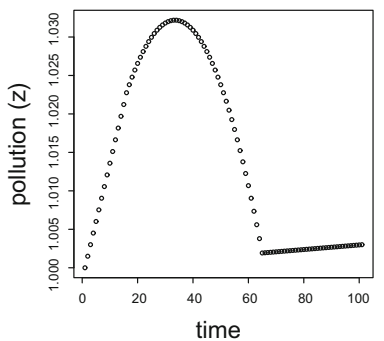

(c)

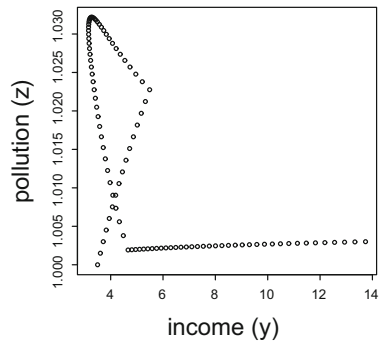

Fig. 4 Dynamics of income (a), pollution (b), and income-pollution relationship (c) associated to a reduction in the manufacturing share of GDP in the case $\phi=0$, along the BGP equilibrium 
of the factors accumulation effect delays the reduction in pollution associated to the sectoral shift, meaning that pollution starts to drop only after a while such that there is a portion of the EKC (immediately after the sectoral shift has taken place) in which reductions in income are accompanied by increases in pollution.

This result allows us to stress the role of the production externality in generating a humpshaped EKC. In absence of such an externality the only situation in which we might observe a bell-shaped income-pollution relationship is represented by economies in which the share of services in GDP is very large ${ }^{16}$ (possibly close to unity), such that the condition in Proposition 4 is met since the beginning of the structural change characterized by a reduction in the manufacturing share. The presence of a production externality (independently on whether this might be positive or negative) increases the likelihood of an inverted-U shaped incomepollution relation to occur as a result of structural change.

\section{Conclusions}

The EKC hypothesis advances the existence of an inverted-U relationship between per capita income and pollution. Several reasons explaining the channels generating a hump-shaped income and pollution relationship have been proposed in the literature. Among these, the structural change has received little attention thus far; such a hypothesis claims that economic growth may generate some structural change which, by shifting the economic production system from high polluting industry to low polluting services, might reduce the environmental pressure associated with increased economic activity.

The goal of our paper is therefore to shed some light on the mechanisms underlying the occurrence of a bell-shaped EKC as a result of structural change. Previous works on structural change and environmental performance have been mainly empirical, and very few papers have tackled the issue from a theoretical perspective. Differently from previous research efforts which rely upon general equilibrium or unbalanced growth models, we develop a traditional BGP analysis consistent with the growth literature.

Specifically, we construct a very general two-sector model of endogenous growth characterized by manufacturing and services. We analyze under which conditions an inverted-U income-pollution relationship may occur due to sectoral shifts reducing the manufacturing share of GDP and simultaneously increasing the share of services. We show that a falling arm of the EKC can occur only if the parameter measuring the intensity of a certain production externality is either small enough or large enough, whereas other factors (such as the green preference and complementarity in manufacturing and services investments parameters) are completely irrelevant for generating such a bell-shaped curve. Thus, if the production externality parameter takes intermediate values (neither too small nor too large) a sectoral shift may not lead to a negative link between pollution and income. The need for the production externality parameter to fall in a certain range of values may also contribute to explain why the empirical evidence on the EKC presents such a mixed picture. Tertiarization is not sufficient for delinking economic growth from environmental degradation. If the technological progressiveness of a growing service sector is not sufficiently high and/or the manufacturing sector is unable to compensate its shrinking share with increased productivity through technological development, we may find that long-run growth may be compromised and

\footnotetext{
16 In order to understand how large the share of services needs to be, we can rely on a specific example. With the parametric values employed in our simulations, it should get larger than 0.97 in order to generate a falling arm. This suggests that the absence of a production externality represents a deterrent for a bell-shaped EKC to occur.
} 
EKC-type dynamics will not take place. This result is in line with recent works such as André and Smulders (2014) that address the role of directed technical change in overcoming the challenge that the exhaustion of essential natural resources poses to long-run growth.

We have also argued that, in the case of an EKC driven by structural change, the negative relation between income and pollution can only be a temporary phenomenon. After a transitory period in which the manufacturing share drops, such a negative relationship will be broken and the economy will restart developing along a BGP, characterized by increases in both income and pollution. Recent trends in advanced economies confirm that sectoral shifts towards (clean) services are occurring and this might explain why it is possible to observe a falling arm of the EKC in some countries; however, such an outcome will not persist indefinitely. The $\mathrm{N}$-shaped income-pollution relationship along the BGP suggests a pessimistic view on the prospect for a sustainable future in a business-as-usual scenario. Indeed, simply promoting economic growth (for example through the liberalization of international trade) cannot be a panacea to fix environmental problems. Thus, it is essential to promote clean technical progress and preservation activities.

Note that the results in this paper have been derived in a stylized framework in which governments (or any other public authorities) do not play any role. Such a simplifying assumption allows us to analyze the problem in its simplest setup but it has some obvious limitations. First of all, remember that we consider structural change to be completely exogenous but in reality it is endogenously determined by economic development; in particular, public policy can play a very important role in promoting an eventual shift from dirtier to cleaner sectors, thus extending the analysis to allow for a public sector might help to explain the sources of the structural change affecting modern economies. Secondly, public policy is to a large extent responsible (directly or indirectly) of purposive environmental protection activities and clean technological progress; introducing these elements in the analysis might allow to better understand what the shape of the EKC might look like in a context of growing environmental concern. Moreover, in such an extended context it may well be the case that government intervention could compensate for the rise in pollution associated with the new rising arm occurring when the structural change is over. Thus, it would be extremely interesting to extend our modeling framework along this direction and study under which conditions a falling arm might be maintained indefinitely.These further issues are left for future research.

\section{Appendix 1: BPG Equilibrium}

From Eqs. (6) and (7), since $u_{t} \in(0,1)$, it is clear that along the BGP we need $\gamma_{k}=\gamma_{x}$ in order for $r_{t}$ and $p_{t}$ to be constant; this implies that also the ratio $\frac{x_{t}}{k_{t}}$ is constant. Household's maximization, along with the state equations and the transversality conditions (TVCs), yields to the following first order conditions:

$$
\begin{aligned}
\lambda_{t} & =c_{t}^{-\sigma} e^{-\rho t} \\
\lambda_{t} p & =\mu_{t} \theta \\
-\dot{\lambda}_{t} & =\lambda_{t} r_{t} \\
-\dot{\mu}_{t} & =\lambda_{t} p_{t} u_{t}+\mu_{t}\left[\theta\left(1-u_{t}\right)+\varphi \gamma_{k}\right]
\end{aligned}
$$

where $\lambda_{t}$ and $\mu_{t}$ denote the costate variables associated to manufacturing and services capital, respectively. Differentiating (18) with respect to time and plugging (19) and (20) into the derived equation yields:

$$
r_{t}=\theta+\varphi \gamma_{k}=r,
$$


which by substituting (6) can be rewritten as:

$$
\frac{u_{t} x_{t}}{k_{t}}=\left[\frac{\theta+\varphi \gamma_{k}}{a(1-\alpha)}\right]^{1-\alpha}
$$

differentiating (17) with respect to time and plugging (21) in the derived equation yields:

$$
\gamma_{c}=\frac{\theta+\varphi \gamma_{k}-\rho}{\sigma}
$$

From (8), we need $\gamma_{k}=\gamma_{c}$ in order to have long run growth and not to violate the TVCs. Thus, we define the economic growth rate as $\gamma \equiv \gamma_{k}=\gamma_{c}=\gamma_{x}=\gamma_{y}$. By solving (23) for $\gamma$, we obtain:

$$
\gamma=\frac{\theta-\rho}{\sigma-\varphi} .
$$

From (9), we can also obtain:

$$
\gamma=\theta\left(1-u_{t}\right)+\varphi \gamma
$$

Equating (24) and (25) yields:

$$
u_{t}=\frac{\theta(\sigma-1)+\rho(1-\varphi)}{\theta(\sigma-\varphi)}=\bar{u} \in(0,1) .
$$

Substituting (24) and (26) into (21)and (22) leads to:

$$
\begin{gathered}
r=\frac{\theta \sigma-\varphi \rho}{\sigma-\varphi} \\
\frac{k_{t}}{x_{t}}=\left\{\left[\frac{\theta \sigma-\varphi \rho}{(1-\alpha)(\sigma-\varphi)}\right]^{\frac{1}{\alpha}} \frac{\theta(\sigma-\varphi)}{\theta(\sigma-1)+\rho(1-\varphi)}\right\}^{\frac{\alpha}{\phi-\alpha}} .
\end{gathered}
$$

The pollution growth rate can be directly found by differentiating (5) with respect to time, which yields:

$$
\gamma_{z}=\psi(1-\alpha) \gamma
$$

Note that since $\sigma>1$ as long as $\theta>\rho$ the growth rate is positive, $\gamma>0$, and the share of services allocated to final production is positive and smaller than one, $\bar{u} \in(0,1)$. Moreover, since $\alpha \in(0,1)$ and $\psi>0$ the growth rate of pollution is strictly positive, $\gamma_{z}>0$, and its relation with $\gamma$ depends on whether $\psi(1-\alpha)$ is larger or smaller than 1 .

Along the BGP, Eq. (28) can be rewritten as:

$$
k_{t}=\left(\frac{r}{1-\alpha}\right)^{\frac{1}{\phi-\alpha}} \bar{u}^{-\frac{\alpha}{\phi-\alpha}} x_{t}
$$

which plugged into (3), along with (4), yields:

$$
y_{t}=\bar{u}^{-\frac{\alpha}{\phi-\alpha}}\left(\frac{r}{1-\alpha}\right)^{\frac{1+\phi-\alpha}{\phi-\alpha}} x_{t} .
$$

This last expression, along with (5), is used to derive the results in Proposition 2. 


\section{Appendix 2: A Different Pollution Specification}

So far we have assumed that services are a totally clean production factor, and such an assumption may be thought to be the main driver of the results presented in this paper. Therefore, in order to understand to what extent such a claim is true, we now consider a more realistic pollution specification, and in particular we assume that pollution depends not only on the manufacturing intensity, as in (5), but also on the services intensity employed in the production of the final consumption good. Specifically, pollution is now given by the following expression:

$$
z_{t}=\eta\left(u_{t} x_{t}\right)^{\psi_{1} \alpha} k_{t}^{\psi_{2}(1-\alpha)}
$$

where $\psi_{1}, \psi_{2}>0$ and $\psi_{1}<\psi_{2}$. This latter parametric condition states that (reasonably) the manufacturing sector has a larger degree of dirtiness than the services sector. As we will show in a while, replacing (5) with (32) leads to results qualitatively not different from those discussed in the main text. Indeed, it is straightforward to show that the economic growth rate and the share of services allocated to final production are still equal to (14) and (16), respectively. However, the growth rate of pollution along the BGP is obviously different from (15), but it is straightforward to verify that it is still strictly positive since it is given by the following expression:

$$
\gamma_{z}=\left[\psi_{1} \alpha+\psi_{2}(1-\alpha)\right] \gamma>0
$$

Note that in the case $\psi_{1}=0$ and $\psi_{2}=\psi$ we are back to the case considered in the main text, since (33) would simplify in $\gamma_{z}=\psi(1-\alpha) \gamma$.

By differentiating (32) with respect to $1-\alpha$, it is straightforward also to show that the relationship between pollution and the manufacturing share of GDP is monotonically increasing if the following condition holds $\psi_{2}>\frac{\psi_{1} \ln \bar{u} \ln x_{t}}{\ln k_{t}}$, which after some algebra can be rewritten as follows:

$$
\psi_{2}>\psi_{1}\left[1+\frac{\ln \left(\frac{1-\alpha}{r}\right)+\phi \ln \bar{u}}{(\phi-\alpha) \ln k_{t}}\right] .
$$

Since by assumption $\psi_{2}>\psi_{1}$, if $\phi>\alpha$, since the second term in the brackets is negative (remember that $\ln \bar{u}<0$ and, since $r>1$, also $\ln \left(\frac{1-\alpha}{r}\right)<0$ ), the relationship between pollution and the manufacturing share is positive (exactly as in Proposition 3, case (ii)). If instead $\phi<\alpha$, a sufficient condition for the second term in the brackets to be negative requires that $\phi$ is negative and smaller than a certain value $\phi<-\frac{\ln \left(\frac{1-\alpha}{r}\right)}{\ln \bar{u}}$ (this additional condition complicates a bit the restriction to be imposed in order to observe a falling arm, but the result is very similar to Proposition 3, case (i)). Again note that if $\psi_{1}=0$ our result of Proposition 3 is reestablished, since (34) would simplify in $\psi_{2}>0$. This means that as long as $\psi_{2}>\psi_{1}$, a hump-shaped EKC is consistent with a sectoral shifts if $\phi<\min \left[-\frac{\ln \left(\frac{1-\alpha}{r}\right)}{\ln \bar{u}}, \frac{\omega-\sqrt{\omega^{2}+4 \epsilon}}{2}\right]$ (similarly to Proposition 3, case (i)) or if $\phi>\alpha$ (exactly as in Proposition 3, case (ii)). If such conditions are met, precisely the same results discussed in the main text hold. This confirms that the specification of pollution as in (5) does not drive our results but it is merely a simplifying assumption, useful to stress that even in the case in which services are totally pollution-free a hump-shaped EKC does not necessarily occur as a response to structural change. 


\section{References}

André FJ, Smulders S (2014) Fuel in growth when oil peaks: directed technological change and the limits to efficiency. Eur Econ Rev 69:18-39

Andreoni J, Levinson A (2001) The simple analytics of the environmental Kuznets curve. J Pub Econ 80:269286

Ang BW (2004) Decomposition analysis for policymaking in energy: which is the preferred method? Energy Policy 32:1131-1139

Ang BW, Liu FL (2001) A new energy decomposition method: perfect in decomposition and consistent in aggregation. Energy 26:537-548

Arrow K, Bolin B, Costanza R, Dasgupta P, Folke C, Holling CS, Jansson BO, Levin S, Mäler KG, Perrings C, Pimentel D (1995) Economic growth, carrying capacity, and the environment. Science 268:520-521

Beckerman W (1992) Economic growth and the environment: whose growth? whose environment? World Dev 20:481-496

Baumol W (1967) Macroeconomics of unbalanced growth: the anatomy of urban crisis. Am Econ Rev 57:415426

Brock WA, Taylor MS (2005) Economic growth and the environment: a review of theory and empirics. In: Aghion P, Durlauf S (eds) Handbook of economic growth, chap 28, vol 1. Elsevier, Amsterdam, pp 1749-1821

Bucci A, Segre G (2011) Culture and human capital in a two-sector endogenous growth model. Res Econ 65:279-293

Carson RT (2010) The environmental Kuznets curve: seeking empirical regularity and theoretical structure. Rev Environ Econ Policy 4:3-23

Cherniwchan J (2012) Economic growth, industrialization, and the environment. Resour Energy Econ 34:442467

Copeland BR, Taylor MS (2004) Trade, growth and the environment. J Econ Lit 42:7-71

de Bruyn SM (1997) Explaining the environmental Kuznets curve: structural change and international agreements in reducing sulphur emissions. Environ Dev Econ 2:485-503

de Groot HLF (2003) Structural change, economic growth and the environmental Kuznets curve: a theoretical perspective. OCFEB Research, Memorandum no 9911

Dinda S (2004) Environmental Kuznets curve hypothesis: survey. Ecol Econ 49:431-455

Duro JA, Alcántara V, Padilla E (2010) International inequality in energy intensity levels and the role of production composition and energy efficiency: an analysis of OECD countries. Ecol Econ 69:2468-2474

Echevarria C (1997) Changes in sectoral composition associated with economic growth. Int Econ Rev 38:431452

Ederington J, Levinson A, Minier J (2004) Trade liberalization and pollution havens B.E. J Econ Anal Policy 3:1-24

Friedl B, Getzner M (2003) Determinants of $\mathrm{CO}_{2}$ emissions in a small open economy. Ecol Econ 45:133-148

Grossman GM (1995) Pollution and growth: what do we know? In: Goldin I, Winters LA (eds) The economics of sustainable development. Cambridge University Press, Cambridge

Grossman GM, Krueger AB (1991) Environmental impacts of the North American Free Trade Agreement. NBER working paper no 3914

He J, Richard P (2010) Environmental Kuznets curve for $\mathrm{CO}_{2}$ in Canada. Ecol Econ 69:1083-1093

Hettige H, Mani M, Wheeler D (2000) Industrial pollution in economic development: the environmental Kuznets curve revisited. J Dev Econ 62:445-476

Holtz-Eakin D, Selden T (1995) Stoking the fires: $\mathrm{CO}_{2}$ emissions and economic growth. J Publ Econ 57:85101

John A, Pecchenino R (1994) An overlapping generations model of growth and the environment. Econ J 104:1393-1410

Kaika D, Zervas E (2013) The environmental Kuznets curve (EKC) theory. Part B: critical issues. Energy Policy 62:1403-1411

Kijima M, Nishide K, Ohyama A (2010) Economic models for the environmental Kuznets curve: a survey. J Econ Dyn Control 34:1187-1201

Kongsamut P, Rebelo S, Xie D (2001) Beyond balanced growth. Rev Econ Stud 68:869-882

Kuznets S (1966) Modern economic growth: rate, structure, and spread. Yale University Press, New Haven

La Torre D, Marsiglio S (2010) Endogenous technological progress in a multi-sector growth model. Econ Modell 27:1017-1028

Laitner J (2000) Structural change and economic growth. Rev Econ Stud 67:545-561

Lopez R (1994) The environment as a factor of production: the effects of economic growth and trade liberalization. J Environ Econ Manag 3:165-177 
Lucas RE (1988) On the mechanics of economic development. J Monet Econ 22:3-42

Maclaurin WR (1954) Technological progress in some American industries. Am Econ Rev 44:178-189

Maddison A (1980) Economic growth and structural change in the advanced countries. In: Leveson I, Wheeler JW (eds) Western economies in transition: structural change and adjustment policies in industrial countries. Croom Helm, London

Mani M, Wheeler D (1998) In search of pollution havens? Dirty industry in the world economy, 1960-1995. J Environ Dev 7:215-247

Maroto-Sánchez A, Cuadrado-Roura JR (2009) Is growth of services an obstacle to productivity growth? A comparative analysis. Struct Change Econ Dyn 20:254-265

Martínez-Zarzoso I, Bengoechea-Morancho A (2004) Pooled mean estimation of an environmental Kuznets curve for $\mathrm{CO}_{2}$ emissions. Econ Lett 82:121-126

McConnell K (1997) Income and the demand for environmental quality. Environ Dev Econ 2:383-389

Mulder P, de Groot H, Pfeiffer B (2014) Dynamics and determinants of energy intensity in the service sector: a cross-country anlisis 1980-2005. Ecol Econ 100:1-15

Ngai RL, Pissarides CA (2004) Structural change in a multi-sector model of growth. CEP Discussion Paper 627

Nickell S, Reddingand S, Waffeld J (2008) The uneven pace of deindustrialization in the OECD. World Econ 31:1154-1184

National Wildlife Federation (1990) Environmental concerns related to a United States-Mexico-Canada free trade agreement. mimeo

Nordhaus WD (2008) Baumol's diseases: a macroeconomic perspective. The B.E J Macroecon 8:1-39

Panayotou T (1993) Empirical tests and policy analysis of environmental degradation at different stages of economic development. Working Paper WP238, Technology and Employment Programme, International Labor Office, Geneva

Panayotou T, Peterson A, Sachs J (2000) Is the environmental Kuznets curve driven by structural change? What extended time series data may imply for developing countries. Center for International Development, CAER II Discussion Paper 80

Pasche M (2002) Technical progress, structural change, and the environmental Kuznets curve. Ecol Econ 42:381-389

Pasinetti L (1981) Structural change and economic growth: a theoretical essay on the dynamics of the wealth of nations. Cambridge University Press, Cambridge

Pezzey JCV (1992) Sustainability: an interdisciplinary guide. Environ Values 1:321-362

Rowthorn R, Ramaswamy R (1997) Deindustrialization: causes and implications. International Monetary Fund, Staff Studies for the World Economic Outlook Washington, December, pp 61-77

Saeger SS (1997) Globalization and deindustrialization: myth and reality in the OECD. Weltwirtschaftliches Arch 133:579-608

Schettkat R, Yocarini L (2006) The shift to services employment: a review of the literature. Struct Change Econ Dyn 17:127-147

Selden T, Song D (1994) Environmental quality and development: is there a Kuznets curve for air pollution emissions? J Environ Econ Manag 27:147-162

Selden T, Song D (1995) Neoclassical growth, the J curve for abatement and the inverted U curve for pollution. J Environ Econ Manag 29:162-168

Sequeira TN, Reis AB (2006) Human capital composition, R\&D and increasing role of services. Top Macroecon 6:1-25

Shafik N, Bandyopadhyay S (1992) Economic growth and environmental quality: time series and cross country evidence, Background Paper for the World Development Report 1992. The World Bank, Washington, DC

Stern DI (2004) The rise and fall of the environmental Kuznets curve. World Dev 32:1419-1439

Stern DI, Common MS, Barbier EB (1996) Economic growth and environmental degradation: the environmental Kuznets curve and sustainable development. World Dev 24:1151-1160

Stokey N (1998) Are there limits to growth? Int Econ Rev 39:1-31

Suri V, Chapman D (1998) Economic growth, trade, and energy: implications for the environmental Kuznets curve. Ecol Econ 25:195-208

Timmer MP (2012) The world input-output database (WIOD): contents, sources and methods. WIOD working paper number 10. http://www.wiod.org/publications/papers/wiod10

Uppenberg K, Strauss H (2010) Innovation and productivity growth in the EU service sector. European Investment Bank

Uzawa H (1965) Optimum technical change in an aggregate model of economic growth. Int Econ Rev 6:18-31

Weber CL (2009) Measuring structural change and energy use: decomposition of the US economy from 1997 to 2002. Energy Policy 37:1561-1570 